\title{
Rafael Estrada y la formación de la crítica estético-literaria costarricense
}

\author{
Rafael Estrada and the formation of Costa Rican aesthetic-literary criticism \\ Francisco Rodríguez Cascante ${ }^{1}$
}

Fecha de recepción: 25-8-20

Fecha de aceptación: 12-4-21

\begin{abstract}
Resumen
Tomando en consideración la teoría de Pierre Bourdieu acerca de los campos culturales, se analizan, en primer lugar, dos estudios del poeta ramonense Rafael Estrada sobre la literatura y la estética: "Al margen de los Fantaseos de Andrés Avelino" (1923) y Sobre los estudios estéticos (1926). Se argumenta que en ellos plantea Estrada sus concepciones sobre el arte de vanguardia frente a las tradiciones romántica y modernista. Tales ideas acerca de la "nueva literatura" convierten a Estrada en un contemporáneo de su tiempo. En segundo lugar, se estudia el prólogo del último libro del autor: Canciones y ensayos (1929). Sobre este, se plantea que Estrada, en tanto recurso de legitimación, busca relacionar su obra con la tradición.
\end{abstract}

Palabras clave: campo cultural, estética, historia literaria, literatura ramonense, Rafael Estrada.

\begin{abstract}
Taking into consideration Pierre Bourdieu's theory about cultural fields, we first analyze two studies by the Ramonense poet Rafael Estrada on literature and aesthetics: "On the Margins of the Fantasies of Andrés Avelino" (1923) and On aesthetic studies (1926). It is argued that in them Estrada raises his conceptions of avant-garde art against the romantic and modernist traditions. Such ideas about the "new literature" make Estrada a contemporary of his time. Second, the prologue of the author's last book is studied: Songs and Essays (1929). Regarding this, it is argued that Estrada, as a source of legitimation, seeks to relate his work to tradition.
\end{abstract}

Keywords: cultural field, aesthetics, literary history, Ramonense literature, Rafael Estrada.

1 Doctor en literatura por la Universidad de Montreal. Profesor catedrático en la Universidad de Costa Rica. Director de la Sede de Occidente. Costa Rica. Correo electrónico: francisco.rodriguezcascante@ucr.ac.cr 


\section{Introducción}

Al poeta, crítico de arte y abogado ramonense Rafael Estrada (1901-1933)² le alcanzó su breve vida para polemizar en el incipiente campo cultural costarricense, con los agentes más prestigiosos, y disentir de las normas centrípetas de dicho campo, al introducir en él los nuevos códigos vanguardistas que para la Costa Rica de la década de 1920 resultaban antiestéticos e incomprensibles.

En un artículo publicado en la Revista de Filología y Lingüística de la Universidad de Costa Rica (Rodríguez Cascante, 2017), planteamos que la obra poética de Rafael Estrada está inmersa en la hibridación entre el intimismo postmodernista y la vanguardia literaria, lo cual la distancia de los cánones formales retóricos del clasicismo. Tal heterogeneidad provocó, a principios del siglo XX, una permanente descalificación del poeta ramonense por parte de los agentes legitimados del campo literario costarricense de aquella época, representados por dos destacados intelectuales herederos del romanticismo: Napoleón Quesada (quien fue director del Liceo de Costa Rica y Ministro de Educación Pública durante la segunda administración del entonces presidente Ricardo Jiménez Oreamuno) y Rogelio Sotela (miembro de la Academia Costarricense de la Lengua, diputado al Congreso, gobernador de San José y el primer historiador de la literatura costarricense).

Tal descrédito llevó a Estrada a polemizar con dichos agentes del campo cultural y a defender las formas expresivas de la "nueva literatura", frente a la tradición romántica y modernista. Este novedoso registro de escritura constituyó la primera producción de literatura de vanguardia en Costa Rica, la cual estuvo mezclada con los modelos postmodernistas. Estas particularidades de la obra de Estrada fueron incomprendidas por el joven campo literario costarricense del momento.

Dicho campo se empieza a articular con relativa autonomía entre 1890 y 1910, cuando se editan una serie de textos que comienzan a configurar la literatura nacional: Máximo Fernández da a conocer la antología La lira costarricense
(1890), Carlos Gagini estrena Los pretendientes (189o), Ricardo Fernández Guardia publica Hojarasca (1894). En 1895 se publica "Nochebuena", el primer cuento de Magón. Entre 1898 y 1900 se dan a conocer las obras históricas y literarias de Manuel Argüello Mora y también en 1900 se publica El Moto de Joaquín García Monge. En la década siguiente, se continúan publicando textos que luego se convertirán en canónicos dentro de la literatura costarricense, así como se consolidan escuelas y discursos literarios. Bien señala, al respecto, Quesada Soto que en la década de 1900 a 1910 "se consolidan las diversas escuelas y discursos literarios" (1995, p. 94) y es entonces cuando se pueden apreciar los primeros "clásicos" de la literatura nacional. Con el paso del tiempo, en el siglo XX pasaron a conformar el canon literario costarricense básicamente dos grupos textuales producidos en la zona central del país: los publicados por la Generación del Olimpo, y posteriormente, los dados a conocer por la Generación del 40.

Junto a ese abanico de producciones literarias en distintos géneros y tendencias, se encuentra el nacimiento, si bien escaso y limitado, de la crítica estética y literaria. Es el trabajo de Antonio Zambrana Ideas de estética, literatura y elocuencia publicado en 1896, el que inaugura la aproximación reflexiva sobre este segmento del campo cultural costarricense. Estamos en presencia de lo que Carlos Francisco Monge y Gabriel Baltodano (2016) denominan la etapa fundacional de la crítica literaria nacional, que abarca desde 1890 hasta 1920, y está conformada por trabajos como Lira costarricense (18901891) de Máximo Fernández, Literatura patria (1913) de José Fabio Garnier, Bocetos: artistas y hombres de letras (1917) de Alejandro Alvarado Quirós, Carta literaria (1918) de Justo Antonio Facio y Principios de crítica (1918) de Moisés Vincenzi. Este período está caracterizado por "la adscripción a los modelos estético-ideológicos más vigorosos en el siglo XIX" (2016, p. 24), con predominancia de los principios estéticos del neoclasicismo.

Un segundo período, estudiado por Monge y Baltodano ,es lo que llaman "La segunda etapa (o etapa de exploraciones)” que corresponde a los años 1920-1950.

2 Debido a su corta vida, la obra de Rafael Estrada se compone, en el ámbito de la producción literaria, de los siguientes poemarios: Huellas (1923), Viajes sentimentales (1924) y Canciones y ensayos (1929). En ensayo publicó Sobre los estudios estéticos (1926). 
En este segundo momento se ubican trabajos como Las categorías literarias (1923) de Roberto Brenes Mesén, La educación estética (1924) de Rogelio Sotela, La cultura literaria (1930) de Justo Antonio Facio y La posición actual de los estudios literarios y lingüísticos (1934) de Isaac Felipe Azofeifa. En este período, apuntan con acierto Monge y Baltodano, "se hace hincapié en los avances de las vanguardias artísticas y sus propósitos transformadores, y con ello en una revisión del canon literario nacional" (2016, p. 27).

Es en este segundo momento, cuando Rafael Estrada publica tres destacados trabajos sobre las producciones estéticas y sus vínculos con la tradición y la ruptura: "Al margen de los Fantaseos de Andrés Avelino" (1923)², Sobre los estudios estéticos $(1926)^{4}$ y su libro Canciones y ensayos (1929). En ellos plantea Estrada sus concepciones sobre el arte de vanguardia frente a las tradiciones romántica y modernista; estas últimas las asume como herencias culturales.

Con fundamento en los postulados teóricos que Pierre Bourdieu propone para el estudio de los campos culturales, este artículo tiene como objetivo el análisis de tales concepciones en los tres textos mencionados. En primer lugar, se presta atención al trabajo "Al margen de los Fantaseos de Andrés Avelino". Se argumenta que Estrada estima definidora de las vanguardias la exploración en el universo de los sentidos y las percepciones del mundo interior de sus autores.

Posteriormente, se estudia el ensayo Sobre los estudios estéticos. Se indica que Estrada, al partir de un paradigma biográfico-intuicionista de la estética, llega a considerar las prácticas artísticas desde el idealismo de las bellas letras. Este paradigma estima el arte como intuición, armonía y belleza, cuyo objeto es la representación fiel de la realidad por medio de la sensibilidad del artista. Ejemplo de este modelo es la teoría estética de Benedetto Croce.
En tercer lugar, se analiza el prólogo del libro Canciones y ensayos. En esta sección se plantea que Estrada recurre, en tanto estrategia de legitimación ante los agentes dominantes del campo cultural costarricense de la primera parte del siglo XX, a la vinculación de la "nueva literatura” con la tradición.

Se propone que el intelectual costarricense asume la ruptura vanguardista como un modelo de exploración de la subjetividad del artista, sin que ello implique transgredir la concepción decimonónica de la estética como deudora del paradigma de las bellas letras y su noción aurática.

\section{Campo estético y poder}

En Las reglas del arte. Génesis y estructura del campo literario, Pierre Bourdieu argumenta que el estudio de las producciones culturales supone tres operaciones fundamentales, todas ellas vinculadas con los distintos niveles de realidad social que aprehenden: a) el estudio de la posición del campo literario en el seno del campo de poder y su evolución temporal, b) el análisis de la estructura interna del campo literario, junto con sus propias reglas de funcionamiento y de transformación. Esto implica la consideración de las relaciones entre las posiciones que en él ocupan individuos y grupos ubicados en situación de competencia por la legitimidad. Y, por último, c) el análisis de la génesis de los habitus de los ocupantes de estas posiciones, dicho sea, los sistemas de disposiciones que, al ser producto de una trayectoria social y de una posición dentro del campo, encuentran en esa ubicación el momento para actualizarse.

De esta manera, las prácticas y representaciones de los artistas solo pueden explicarse tomando como referencia el campo de poder dentro del cual el campo estético ocupa una cierta posición. El campo de poder es definido como:

el espacio de las relaciones de fuerza entre agentes e instituciones que tienen en común el poseer

3 Este trabajo se divide en tres partes, cada una publicada por separado en Repertorio Americano. La primera el 29 de octubre de 1923 , la segunda el 5 de noviembre de 1923 y la tercera el 19 de noviembre de 1923.

4 Este estudio, que fue publicado en forma de libro por la Imprenta Alsina en 1926, un año antes fue dado a conocer en Repertorio Americano en cuatro entregas entre el 12 de octubre y el 16 de noviembre de 1925. Para efectos de citación, se utiliza la edición de la Imprenta Alsina. 
el capital necesario para ocupar posiciones dominantes en los diferentes campos (económico y cultural en especial). Es la sede de luchas entre ostentadores de poderes (o de especies de capital) diferentes, como las luchas simbólicas entre los artistas y los "burgueses" del siglo XIX, por la transformación o la conservación del valor relativo de las diferentes especies de capital que determina, en cada momento, las fuerzas susceptibles de ser comprometidas en esas luchas (Bourdieu, 1995, pp. 319-320).

Así, propone el teórico que el grado de autonomía del campo y por ende, del estado de las relaciones de fuerzas que en él se instauran, varía mucho de acuerdo con las épocas y las tradiciones nacionales. Todo depende del capital simbólico que se ha ido acumulando con el paso del tiempo mediante la acción de distintas generaciones sucesivas, lo cual otorga poder simbólico a los agentes involucrados en las disputas por el poder a lo interno del campo.

Con base en estas ideas, el autor afirma que es posible superar la oposición entre lectura interna y análisis externo sin perder los aportes de ambos enfoques, y más bien se recupera la dimensión relacional propia de las vinculaciones intertextuales. Fundamentado en esta distinción, Bourdieu propone la existencia de una "homología entre el espacio de las obras definidas en su contenido propiamente simbólico, y en particular en su forma, y el espacio de las posiciones en el campo de producción" (1995, p. 308). Considerando el ámbito de la producción literaria, esto significa que la mayor parte de las estrategias literarias están sobredeterminadas y sus elecciones son actos estéticos y políticos al mismo tiempo, es decir tanto internos como externos.

Por otra parte, el poder al interior del campo estético funciona mediante la acumulación de capital simbólico, lo cual otorga distinción a los agentes. Esta capacidad adicionadora articula la creencia en la legitimidad, dicho sea produce la illusio, "como ilusión de realidad colectivamente compartida y aprobada” (Bourdieu, 1995, p. 484). Son estas nociones de distinción e illusio las que regulan las luchas por el control semiótico y su valor tanto a lo interno como a lo externo de los campos culturales.
En su teoría estética, Rafael Estrada establece una polémica con la tradición asumida por los agentes legitimados del joven campo cultural costarricense, ante el rechazo de tales actores de las nuevas corrientes vanguardistas. Sin embargo, el autor no plantea la sustitución de un modelo antiguo por uno nuevo, sino, más bien, pugna por el reconocimiento de las vanguardias en tanto formas que no renuncian a la tradición, por el contrario, estima que las nuevas expresiones estéticas conllevan en sus niveles experimentales las mismas "sustancias" artísticas invariables en el devenir temporal.

\section{Vanguardia y poética: la defensa del postumismo}

En el trabajo "Al margen de los Fantaseos de Andrés Avelino", realiza Estrada una decidida defensa de la poesía del escritor dominicano. Cabe recordar que Andrés Avelino García (1900-1974) fue fundador del movimiento vanguardista dominicano postumista, junto con Domingo Moreno Jimenes (1894-1986) y Rafael Augusto Zorrilla (1892-1937).

El movimiento dirigido por los tres autores publicó El día estético. Revista Indo-universal de vanguardia, la cual tuvo "una muy importante función renovadora en las letras dominicanas, especialmente con la incorporación plena del versolibrismo y la ruptura con las trabas formales del modernismo" (Osorio, 1988, p. 111).

El movimiento fue de amplia relevancia en República Dominicana. Como afirma Diógenes Céspedes: "A pesar de lo que se diga, la recepción del postumismo fue casi masiva en los círculos literarios de la capital, Santiago, San Pedro de Macorís y El Seibo, para no mencionar otras ciudades donde el peregrinar de un apostolado mesiánico llevó a Domingo Moreno Jimenes, y a otros miembros prominentes y adeptos del grupo" (1985, p. 44).

De acuerdo con Gloria Videla, la vanguardia hispanoamericana tiene dos caras: una que mira hacia el pasado inmediato con la intención de romper con ella, es pues una actitud de rebeldía, iconoclasta y destructiva que lucha contra la mímesis, el simbolismo y el modernismo. Tal actitud procura romper con los temas y formas de 
prestigio poético de la tradición. La otra cara mira al futuro, los autores "quieren gestar el porvenir, inaugurar una nueva era, cambiar rumbos" (2011, p. 22). Se encuentran, entonces, búsquedas formales e incorporación de nuevos temas y tonos anticonvencionales. Recuérdese, como ejemplo, las experimentaciones lingüísticas que realizó Vicente Huidobro en Altazor (1931), donde rompe con los esquemas clásicos de la comunicación literaria. ${ }^{5}$

Este rostro bifronte está presente en el postumismo. Justamente es en el libro que comenta Estrada, Fantaseos (1921) de Avelino García, donde aparece el Manifiesto postumista, cuyas premisas apuntan tanto a una ruptura con la tradición como a una apuesta por el futuro. Así lo indica el punto J del manifiesto:

Reaccionaremos a la vez contra el romanticismo de Hugo y contra el realismo de Balzac. Pero nada de malabarismos estéticos ni musicales. Rubén Darío ha muerto. Cada acto debe ser una palabra escrita, y la belleza emocional de ese acto: ritmo y ese ritmo: música. Reaccionaremos también contra los ultraístas, futuristas y creacionistas que pretenden en "acrobacia azul" y sobre grupa de aeroplanos ir a conquistar un más allá escondido tras las nubes (En Osorio,1988, p. 110).

De esta manera, y siguiendo los postulados de su propio manifiesto, la poética defendida por Andrés Avelino apuntaba a una negación del pasado reciente, específicamente el romanticismo, el realismo y el modernismo, pero al mismo tiempo se rebelaba contra los excesos experimentales de los grupos más radicales de las vanguardias. Con ello, queda claro que la posición del grupo postumista fue una apuesta por la renovación expresiva de la tradición decimonónica pero sin caer en las aventuras irracionalistas de la mayoría de los movimientos vanguardistas (ultraísmo, futurismo, creacionismo). Se puede señalar, entonces, que la vanguardia defendida por el postumismo fue moderada, puesto que implicaba transgredir la tradición y, al mismo tiempo, defender el valor poético de dicha tradición.
Esta moderación es la que defiende Rafael Estrada en su análisis de la poesía de Avelino García. Estrada está consciente de que los movimientos de vanguardia muestran una nueva "fisonomía del mundo" (Osorio, 1981, p. 229), aquella producida por la Primera Guerra Mundial y la Revolución rusa, aunque el poeta costarricense no plantea sus comentarios en términos sociológicos o históricos, pero sí advierte como rasgos de las nuevas escuelas una recurrencia del artista hacia su interioridad, consecuencia de la insatisfacción con la realidad.

La cercanía de Estrada con el movimiento postumista no se limita al estudio de la obra de Avelino, ni a su amistad con él, sino que una selección de poemas del costarricense fue publicada por Andrés Avelino en su Pequeña antología postumista (1924), lo cual evidencia que la obra de Estrada era vista como eminentemente vanguardista por uno de los fundadores del postumismo.

En su análisis del poemario Fantaseos, desde el punto de vista teórico, Estrada se fundamenta en la concepción estético-moral del escritor británico John Ruskin (1819190o), quien defendía que el poeta no tiene en su vida más que dos finalidades: ver y sentir, gracias a lo cual Ruskin, de acuerdo con Elsa Plaza (2001, p. 150), condenó el arte renacentista por sus deseos de arribar a la ciencia y a la perfección, en tanto que alabó la estética gótica por estimarla cercana a la humildad y la sinceridad. Ruskin consideraba que lo principal del trabajo estético era someterse a los principios morales del bien y la verdad.

Esta dimensión estética es la que predomina en aquellas tendencias críticas de inicios del siglo XX que se oponen al positivismo, especialmente en el biografismo y la estilística. Bien sostiene Ligia Bolaños que la teoría literaria se amplía y se construye sobre la tríada verdad, bondad y belleza. En esta dimensión "la literatura, además de cumplir una función estética, debe ser ética, es decir verdadera y buena” (Bolaños, 1991, p. 200).

Estrada se hace eco de estas nociones y afirma que, en contraposición con el crítico, quien emplea una mirada inmersa en la frialdad científica del razonamiento y en lo

5 Por ejemplo, en el Canto VII de Altazor se lee: "Ai aia aia / ia ia ia aia ui / Tralalí / Lali lalá / Aruaru / urulario / Lalilá / Rimbiblolam Lam Lam / Uiaya zollonario / lalilá / Monlutre la monluztrella / lalolú” (Huidobro, p. 208). 
positivo de los hechos, el artista "vuela libremente hacia lo desconocido, en constante búsqueda de lo eterno, lo divino, lo verdadero" (1923a, p. 83). De esta manera, el rango de acción del artista supera en mucho al del analista, y tal situación explica el hecho de la incomprensibilidad de muchos artistas en lectores que están limitados por sus lógicas de recepción.

Tal incomprensión, de acuerdo con Estrada, ha ocurrido históricamente cuando aparece un sujeto o un grupo innovador. Esto es lo que, para el autor, acontecía en el campo literario costarricense con la aparición de las corrientes de vanguardia:

Créese, por una mayoría a intervalos largos dominante, que todos esos "ismos" pueden considerarse aisladamente, y se les mira en sus extravagancias de escuela y sus características, si acaso declarándoseles en muchas ocasiones como cosas "que no valen la pena discutirse", que sencillamente son "disparatadas"; nada más cómodo que emitir una opinión de esa índole (1923a, p. 83).

Sin embargo, aclara el autor, que no es de interés defender todas las nuevas escuelas en todas sus manifestaciones ya que eso significaría analogar tendencias bastante disímiles, y a Estrada le importa observar en el proceso de renovación vanguardista aquellas expresiones literarias que contemplen como principio el valor estético.

Este elemento que otorga literaturidad al mensaje verbal poético lo encuentra el autor no en las formas mismas ni en los contenidos, sino en el enunciador, en el sujeto que es capaz de hacer un viaje a su interior para captar de una manera diferenciada el universo. Asunto este que Estrada observa como una constante en las literaturas europeas y latinoamericanas posteriores a los finales del siglo XIX. Es, asimismo, un movimiento intenso que ha seguido su curso hasta la década en que escribe el autor, y lo mira como un desbordamiento: "y es que sus manifestaciones son poderosas y múltiples: nos circunda, nos sorprende" (1923a, p 84) e incluso, afirma, "llega a atolondrarnos" (1923a, p. 84).
Tal falta de explicación, ante ese conjunto heterogéneo de discursos que bombardean la estabilidad del campo literario latinoamericano (orden generado por el prestigio y la distinción del modernismo y el realismo que habían establecido con firmeza sus cánones), mediante la experimentación y la valoración de órdenes representacionales ajenos al racionalismo positivista, la intenta resolver Estrada recurriendo a la idea de que las vanguardias se distancian de la mímesis para atender el universo de los sentidos y las percepciones del mundo interior de los autores, lo que el ramonense denomina como "evolución hacia adentro":

Hay cierto romanticismo que no es romanticismo, una especie de suprasensibilidad que pudiéramos llamar ingenua; no encontramos hoy día poetas, poetas de las nuevas generaciones, que nos hablen, como antaño, de las bellezas externas y vibrantes de la naturaleza que nos rodea (...); todos nos hablan de lo que un recuerdo, una emoción, les hace descubrir en su alma, algo que está ligado con su vida, con lo más profundo de su vida, con su alma, en fin, que es decir, con la vida de todos, y que son precisamente los puntos de relación en que se esconden los principios vitales de todos los seres, de todas las cosas del universo, acercándose así a los oscuros e insondables misterios (1923a, p. 84).

Estas fuerzas que obligan a los artistas a explorar y mostrar su subjetividad son las que explican esas diversidades de formas expresivas que al distanciarse de la mímesis de la naturaleza, conducen vía hacia adentro a nuevos universos que exhiben mejor la condición humana.

Las diferencias entre los artistas y, por ende, entre los movimientos de vanguardia, son, entonces, de forma, ya que, indica Estrada, todos buscan las mismas interioridades, por medio de diversidad de recursos:

los poetas expresan, o intentan expresar, la profundidad que descubren en su alma, en la forma que mejores condiciones ofrece a su intelecto, o que mejor comprenden; los unos externan sus concepciones en las difíciles espontaneidades del 
verso libre; otros recurren a frases incoherentes al parecer y que a primera vista causan antipatía; los hay que, con el mismo fin que estos, de dejar a la capacidad receptiva del lector la adquisición de ideas que pueden concebirse en múltiples formas, y que, por consiguiente, no pueden ni deben precisarse, inventan términos y giros de palabras y hasta frases enteras que suscitan el advenimiento de ideas que se sugieren, hay quienes, más incomprensibles aún, colocan las palabras sueltas, regadas, a veces una en cada página, a veces agrupadas dibujando círculos, triángulos, arañas, torres, etc., y ofreciéndonos una literatura a veces ridícula, a veces hasta indecorosa (1923a, p. 84).

A fin de cuentas, entonces, todos los movimientos de vanguardia buscan una misma finalidad: la expresión de la interioridad humana mediante formas diferenciadas, de las cuales nacen las distinciones, no así del fondo, que articula las mismas preocupaciones de los seres humanos de distintas geografías. En esto coincide Estrada con la crítica contemporánea, en el sentido de que los fenómenos de las vanguardias artísticas tuvieron una "condición internacional" (Osorio, 1981, p. 227) compartida, en tanto reacciones a la crisis mundial provocada por la Primera Guerra Mundial y la Revolución rusa.

En este panorama, ¿qué lugar ocupa la poesía de Andrés Avelino? De acuerdo con Estrada, no llama tanto la atención las formas del verso libre que emplea el autor postumista, sino más que nada la "influencia de la evolución hacia adentro" (1923a, p. 84), y concretamente cuatro modalidades de elevación o intensidad.

La primera tiene que ver con la enunciación de lo inexpresable o difícil de comunicar, la segunda con la revelación de los matices del alma del artista, en cuanto motivos o acontecimientos vitales que marcaron al sujeto. En este sentido, la poesía es capaz de mostrar el conocimiento interior, el reino de la conciencia subjetiva y el alma misma del artista:

Una conciencia de lo que se tiene en sí mismo; cuando menos, significaría un intento, si no una preocupación constante, de conocerse, o, menos si se quiere, una curiosidad que lleva a prestar atención a ciertos hechos, que han sido hasta hoy indiferentes, y que son en verdad revelaciones (Estrada, 1923b, 105).

La siguiente modalidad consiste en la expresión de los hechos emocionantes sin expresar la emoción; esto significa que el poeta se limita a describir las situaciones que tienen la facultad de generar emociones, sin que él exprese las suyas. La cuarta modalidad constituye la observación de los motivos irreales, hechos que se suceden sin que se sepa por qué ocurren y que obedecen a fuerzas desconocidas.

Cabe señalar que es la última variante una de las que más valora Estrada, ya que esta vincula la poesía de Avelino con la dimensión aurática del arte, especie de "puerta sagrada" (Estrada, 1923c, p. 138) ante la cual el sujeto se acerca a lo inexplicable. En este ámbito expresivo, estamos en presencia de una fuerza sutil imposible de analizar lógicamente, se trata de una supuesta lógica cósmica y universal que solo pueden percibir los poetas, en tanto seres dotados de una sensibilidad especial negada para las mayorías. "Tocamos-sostiene Estrada- precisamente los orígenes del arte, las vibraciones de que son susceptibles únicamente esa clase de hombres que se llaman poetas, pintores, escultores, músicos,...artistas!” (1923c, p. 138).

Con claras resonancias teosóficas, estas nociones que relacionan la estética con la "lógica cósmica" o las "vibraciones" del universo remiten a la larga tradición bellaletrística que asimilaba la producción artística con la idea del "autor/genio, poseedor del saber y artífice de la lengua” (Bolaños, 1991, p. 198). Nos encontramos en un marco epistemológico que entiende el arte como sustancia transtemporal que se deposita en sujetos dotados de una sensibilidad particular, lejana a las prácticas de la cotidianeidad. Por ello, Estrada no vincula en ningún momento algo fundamental en la construcción del campo literario en la década de 1920 del siglo XX: la relación entre vanguardia estética y vanguardia política. A pesar de ello, su aporte es el reconocimiento y defensa de las vanguardias literarias, y su lucha porque estas ocuparan un lugar en el campo literario costarricense 
de principios del siglo XX. La única forma que distinguió para ello, ante el rechazo generalizado de los agentes de poder del campo de su tiempo, fue la articulación de las vanguardias con los mismos principios auráticos (el arte como misterio y exclusividad letrada) que legitimaban tanto al romanticismo, al realismo y al modernismo.

Tres años después de la publicación del estudio sobre Fantaseos, Estrada dio a conocer, también en Repertorio Americano, un comentario sobre el poemario de Avelino titulado Cantos a mi muerta viva (1926). En dicho trabajo, titulado "Página lírica de Andrés Avelino" reitera la idea de que la poesía debe tener un valor artístico antes que todo. Señala el hecho de que Avelino cultiva una poesía considerada por la gran mayoría como "amorfa"; sin embargo, sostiene Estrada, el poeta dominicano desarrolla un trabajo "purista de las orientaciones poéticas" (1926a, p. 42).

Con esta noción del purismo estético entiende Estrada el esfuerzo por enunciar el cultivo de las formas poéticas orientadas a la expresión de los senderos subconscientes de la subjetividad, en tanto formas de comunicación de la "esencia" del espíritu del poeta, mediante textos portadores de un "acento más hondo y más inefable" (1926a, p. 42). De esta manera, continúa Estrada valorando la expresión poética de Andrés Avelino dentro de los cánones auráticos con los que observa los poemas de Fantaseos, libro que estima insuperado respecto a Cantos de mi muerta viva.

\section{Las trampas de la teoría estética: Sobre los estudios estéticos}

Refiriéndose a Sobre los estudios estéticos, afirma Mario Fernández Lobo que el trabajo de Estrada, al constituirse como una crítica a la estética, lleva al autor a la imposibilidad de la explicación de las "manifestaciones del arte contemporáneo” (1959, p. 57).

Y es que, efectivamente, Sobre los estudios estéticos (1926) pretende constituirse en una continuada reflexión sobre los movimientos de vanguardia, aunque su autor, a diferencia del ejercicio crítico que efectúa en sus comentarios sobre Avelino García, cae en la trampa de acudir a un modelo analítico en el cual no cree: la estética, entendida esta en tanto “Crítica de Arte” (Fernández Lobo, 1959, p. 56).
Justamente la motivación del ensayo tiene que ver con la solicitud que a Estrada le hizo la Asociación de Estudiantes Universitarios de Costa Rica en cuanto a que si tenían fundamento razonable las escuelas de vanguardia. El autor procura responder acudiendo a la estética, debido a que estima este ejercicio como un "comentario sobre la actividad artística" (1926c, p. 5), puesto que no posee carácter propio; es decir, para Estrada la estética, al ser una práctica, no constituye un subcampo disciplinario dentro del campo cultural.

De acuerdo con Estrada, una gran diferencia entre la ciencia y la estética es que mientras que la ciencia confirma continuamente los postulados de la filosofía, la estética, en tanto filosofía de la belleza, encuentra constantes negaciones por parte de la ciencia. Nótese que en este paradigma de validación del saber, corresponde a la filosofía el pedestal mayor en la cadena de disciplinas, y es ella, elevada al rango de ciencia del conocimiento, la que legitima los saberes. Así lo dice Estrada: "la estética tendrá siempre su expresión más alta en el elemento filosófico" (1926c, p. 9). En este modelo, el campo cultural está regulado por la primacía de la filosofía.

Estamos en presencia de un paradigma epistemológico idealista, que sigue la teoría estética croceana. Recuérdese que para el autor italiano, "el arte es visión o intuición. El artista produce una imagen o fantasma, y el que gusta del arte dirige la vista al sitio que el artista le ha señalado con los dedos y ve por la mirilla que este le ha abierto y reproduce la imagen dentro de sí mismo" (1938, p. 21).

En este ámbito, Estrada también recoge la tradición conservadora que inaugurara en Costa Rica Rogelio Sotela con su tesis La educación estética (1924), en la cual plantea que "la estética es armonía, como es armonía la belleza; y en ese sentido, la estética es un control precioso para el hombre, es un Dios que vigila los impulsos y ordena con suavidad los sentimientos" (1924, p. 51).

Este paradigma biográfico-intuicionista de la estética, que antes que práctica es acto de iluminación de sujetos letrados privilegiados, deviene en una de las limitaciones del escrito de Estrada. Como lo afirma Carlos Francisco Monge, en el ensayo de Estrada es muy evidente la 
comprensión de la estética como actividad que se ocupa de elaborar comentarios "sin trazar derroteros ni doctrinas" (2005, p. 6o). A este nivel de generalización se une el hecho de ubicar el arte en ese espacio superior, imposible de traducir en términos histórico-políticos, lo cual sustrae cualquier consideración coyuntural.

Considerando el ejercicio del esteta en estas reflexiones, sostiene Estrada que le corresponde examinar las causas de los fenómenos estéticos, y en este trabajo debe apoyarse en la psicología y en la historia (llamadas por el autor ciencias auxiliares generales), pero principalmente en la primera, ya que ella le permite "conocer el mundo espiritual en que vive el artista” (1926c, 15). La historia es vista en este paradigma como filosofía de la evolución humana, antes que conjunto de prácticas sociales; por ello no tiene mayor relevancia para el conocimiento de los sentimientos y las intuiciones, puesto que están dadas por una sustancialidad a-histórica inherente a la condición espiritual humana.

Además de tales ciencias auxiliares generales, están las ciencias auxiliares especiales que ayudan en el trabajo del comentario estético; son, por ejemplo, la métrica, la armonía, la perspectiva, y colaboran en tanto son ciencias de valor técnico que determinan las formas de las artes, como la música, la poesía, la pintura, entre otras.

Como corolario de esta exposición acerca del trabajo del esteta, sostiene Estrada que la "Estética y la Crítica de Arte viene a constituir una sola entidad” (1926c, p. 19), ya que una crítica de arte razonada es, al mismo tiempo, un compendio de estética. Esta conclusión lo lleva a clasificar en las siguientes categorías los estudios estéticos: a) según la filosofía que los caracterice; b) según predomine en ellos una de las ciencias auxiliares generales; y c), según tenga preponderancia en el autor una $\mathrm{u}$ otra de las ciencias auxiliares especiales.

Luego de tales señalamientos, acude Estrada a mostrar un ejemplo de este empleo de categorías. Acude al estudio del psicólogo alemán Ernesto Meumann (1862-1915) Sistema de estética (1914) y concluye, al respecto, que son muchos los casos en que existen contradicciones dentro de las ciencias auxiliares generales y las especiales.

Tal mostración conduce a la última sección del trabajo de Estrada, donde afirma que la estética no tiene, como la filosofía y el arte, vida propia, ya que se ubica en un sitio posterior al del artista y se subordina a las filosofías, también a las deficiencias de los estudios auxiliares y a las fluctuaciones de las ciencias especiales de las artes. Ante este camino cerrado, concluye sosteniendo que "no encontraremos en los estudios estéticos el alto mirador que buscábamos para comprender el arte contemporáneo" (1926c, p. 30), y ante tal fracaso afirma que "para hablar de 'nuestra' época literaria, debemos desvanecer muchos prejuicios: soltarle las amarras al corcho para empezar a pensar" (1926c, p. 32).

Así entonces, no podía responder Estrada la pregunta planteada por la Asociación de Estudiantes Universitarios de Costa Rica y tampoco le era posible resolver el problema inicial de Sobre los estudios estéticos. El trabajo se queda en una crítica a la estética de su tiempo y en la sugerencia de que se debe buscar la explicación a las manifestaciones vanguardistas en otros lugares, imposibles de mirar, en ese momento, para Estrada. Más allá de las generalizaciones idealistas, la sugerencia valiosa del trabajo es que la literatura contemporánea supone una racionalidad distinta y que no se puede comprender con los criterios de la estética. El camino consiste en "empezar a pensar en la poética, en la poesía de nuestro tiempo" (1926c, p. 32).

Sin embargo, hay que destacar que para la comprensión de la literatura deja claro Sobre los estudios estéticos que en primer lugar se deben conocer los paradigmas críticos desde los que es posible hacer las consideraciones. Estrada estima que la estética de su tiempo no resulta apropiada para el estudio de la literatura de vanguardia, por ello insiste en volver los ojos hacia la intuición ${ }^{6}$ para

6 Esta misma noción de la crítica literaria como intuición la propone Estrada ese mismo año de 1926 al comentar el trabajo de Francisco Villalobos Crítica americana: "Sentimental o intuitiva, como quiera llamársele, por esa plausible actitud mental de interpretación interna, de convivio íntimo con los autores que estudia. A la manera de un profesor de ocultismo, al transportarse al reino interno de cada artista, siente en sí mismo, por contraste o por simpatía, las dolencias que aquejan o las virtudes que exaltan al artista” (1926b, p. 123). 
valorar lo novedoso, circunstancia propia del desarrollo y transformación del arte.

Esta imposibilidad explicativa del ensayo de Estrada es comprensible por tres razones fundamentales. En primer lugar, Estrada escribía en el mismo momento de producción de los movimientos vanguardistas, por lo cual no poesía el necesario distanciamiento temporal para evaluar las producciones que aparecían ante sus ojos y de las cuales él también participaba. Incluso Estrada dudaba en cómo denominar tales escrituras, por un lado las llamaba modernistas y por el otro "ismos": cubistas, novismas, etc. La contemporaneidad, de la cual él era partícipe, le generó una constante sorpresa, ante cuya novedad y oscuridad era un curioso y agudo observador.

En segundo lugar, Estrada luchaba contra el enorme peso de la descalificación de los agentes más poderosos del campo cultural de su época. Eran sujetos que diariamente lo descalificaban y muchas veces, ocultos en el anonimato, lo ridiculizaban y se burlaban de las nuevas manifestaciones estéticas, creyéndolas expresiones absurdas. Este encono llegó, por ejemplo, a posibilitar actos paródicos, como el escrito que publicó alguien con el pseudónimo de Penélope a propósito de la publicación del poemario Huellas (1923) de Estrada. El texto presenta el título de "Huellas de la semana". Se trató de un poema paródico de lo que estimaba Penélope era la forma de la poesía vanguardista de Estrada, dice, por ejemplo:

Han llegado los aeroplanos,

volarán sobre San Ramón,

de lejos se verán enanos,

y rubricarán los arcanos

con jeroglífica intención (...)

No te comprenden los ignaros,

sigue poeta escribiendo mal.

¿Para qué el ritmo, a qué la métrica?

Deja a los otros la aritmética.

Toda tu familia, ¿qué tal? (1924, p.10).
Asimismo, a propósito del poemario de Estrada titulado Viajes sentimentales (1924), alguien con el pseudónimo de Waldemar Walmar, escribió un artículo de nombre "Brosas modernistas", donde se burla de la escritura de Estrada. Dice una parte del texto:

Una de esas tardes que en poemas florecen y en jumas revientan, cuando principiaba el nacimiento de la noche y terminaba la bebida, con el espíritu alegre y la mente embrutecida, me sentí poeta sin haber nacido. (...)

Un viajero en encanijada cabalgadura con su lío de modernismos puestos al anca, en alforjas de mecate y camino a San Ramón, se atraviesa en mi ardorosa fantasía, y mis anhelos quedan como una efigie de leyenda $(1927,3)$.

En tercer lugar, no tenía disponible la Costa Rica de principios del siglo XX, ni una tradición crítica ni mucho menos el instrumental teórico para comprender que el arte es una producción humana inmersa en la dinámica socio-histórica de la tradición y la ruptura. La crítica literaria del período constituía un ejercicio libre donde la valoración subjetiva era la norma. Al no poseer ese capital cultural, Estrada no tuvo otra opción que recurrir a lo ya conocido y legitimado: la concepción aurática del arte, la filosofía como modelo superior explicativo y la tradición estética de su tiempo, con todas las limitaciones que ello implicaba para acercarse a las nuevas manifestaciones de las vanguardias. No había en aquella Costa Rica una crítica literaria mínimamente solvente.

En esta coyuntura, mucho hizo Rafael Estrada, un joven que, contra su época, pudo distinguir que se estaba generando un cambio en los paradigmas estéticos de su tiempo, transformación que el incipiente campo cultural de su momento histórico no comprendió, puesto que aún estaba inmerso en los cánones románticos y modernistas.

Estrada fue un contemporáneo de su tiempo, puesto que, como indica Giorgio Agamben aquel sujeto contemporáneo no coincide con su época debido a que establece una relación de desfase y anacronismo. Este carácter inactual le permite a dicho sujeto percibir más que las luces de su 
tiempo, su oscuridad. Ser contemporáneo significa poder mirar la oscuridad de su tiempo, a diferencia de quienes logran únicamente ver la claridad más evidente. Señala el filósofo italiano:

Percibir en la oscuridad del presente esa luz que trata de alcanzarnos y no puede: eso significa ser contemporáneos. Por eso los contemporáneos son raros; y por eso ser contemporáneos es, ante todo, una cuestión de coraje: porque significa ser capaces, no solo de mantener la mirada fija en la oscuridad de la época; sino también de percibir en esa oscuridad una luz que, dirigida hacia nosotros, se nos aleja infinitamente. Es decir, una vez más: ser puntuales en una cita a la que solo es posible faltar (Agamben, 2006, p. 23).

El campo cultural costarricense debió esperar todavía mucho tiempo para entender las nuevas corrientes de vanguardia, esas nubes de oscuridad que logró distinguir el poeta ramonense. La escritura de innovación que significa el trabajo artístico y crítico de Rafael Estrada necesita seguirse estudiando y valorando.

\section{En busca de la tradición: Canciones y ensayos}

Canciones y ensayos (1929) fue el último poemario publicado por Estrada. El poeta tenía en ese entonces tan solo veintiocho años, fallecería tres años más tarde. Su último poemario fue mejor recibido por la crítica. Federico de Alba señaló en La Nueva Prensa que "desde el principio al fin de esta admirable obra, encontramos oro de belleza pura, oro puro de superior quilataje" (1929, p. 5). Por su parte, el poeta colombiano Eduardo Uribe, dijo que su obra "se categoriza por el máximun de cualidades individuales que la destaca como una de las más ricas y auténticas en la abundante producción literaria centroamericana" (1929, p. 357). Asimismo, Manuel Antonio Bonilla se preguntó: “Hay quién niegue a los cantos y a los versos de Estrada sentimiento, ternura, corazón: Belleza? (1929, p. 7).

Sin lugar a dudas, esta situación obedece a que la publicación de Canciones y ensayos constituye una nueva estrategia empleada por Estrada frente a los agentes legitimados del incipiente campo literario costarricense de su tiempo, en el sentido de que el poemario se concibe en situación de competencia por la legitimidad, en un espacio de lucha por el reconocimiento de su escritura a lo interno del campo. Estrada da un giro; ahora, antes que el enfrentamiento, procura mostrar ya no los distanciamientos de su poesía respecto a la tradición, sino sus vínculos.

Esto lo evidencia el prólogo de la obra. De manera concisa, inicia Estrada diciendo que "He recopilado, en este tomo, poemas escritos a base de una influencia directa de los clásicos; de aquellos clásicos que llamarían, los neocríticos de hoy, modernistas” (1929, p. 7).

Esta referencia procura invalidar la idea que prevalecía en el campo literario costarricense acerca de que la poesía de Estrada significaba una absurda búsqueda de innovación, ajena a toda la tradición tan valorada, especialmente aquella tributaria de los modelos formales del clasicismo.

Cabe recordar que Estrada, por falta de distanciamiento histórico, no tenía clara la diferencia entre las vanguardias y el modernismo. Él mismo se consideraba modernista al mismo tiempo que veía las transformaciones de lo que luego se llamarían los movimientos de vanguardia. En su situación, él comprendía la existencia de los "ismos" pero no lograba diferenciar claramente las profundas rupturas que estos significaban respecto al modernismo. De esta manera, propone Estrada que no existe contradicción al estimar que los movimientos de vanguardia no establecían una separación tajante respecto a la tradición. Para él, las vanguardias eran comprendidas como movimientos que buscaban la expresión de la subjetividad, tal como lo demuestra su valoración de la poesía de Andrés Avelino.

Estamos en presencia de un entendimiento de los movimientos vanguardistas como escrituras híbridas entre la tradición y la renovación. Por ello Estrada se consideraba un escritor modernista, puesto que veía dicho movimiento como una no radical separación del pasado:

En mi medio he sido yo un modernista; he debido engañarlos, publicando poemas del grandioso Juan Ramón Jiménez con la firma mía; me he 
visto obligado a presentarles un análisis de la mentalidad del esteta a fin de demostrarles su impotencia; y luego, heme visto obligado, ante las provocaciones, a enseñarles términos científicos de la nueva métrica (1929, p. 7).

Efectivamente, Estrada se dedicó a una misión pedagógica que tuvo como norte la defensa del arte nuevo que él entendía como modernista, como una serie de expresiones que pertenecían a un sistema estético coherente. Para Estrada no existía todavía distinción entre modernismo y vanguardia. En varios escritos (Estrada, 1927a; Estrada, 1927b; Estrada, 1927c) reclama la ignorancia del público lector y de sus detractores, para argumentar que el modernismo no renuncia a la tradición. Con base en esta noción, abona una idea más a su concepción del arte vanguardista: no es un movimiento, como se conoce en la actualidad, que establece una férrea oposición respecto al pasado y propone visiones acerca del futuro, sino una tendencia que se ubica en el presente y proyecta el porvenir. Con esta estrategia, valida Estrada la articulación que desea entre tradición y vanguardia:

La nueva poética tiene profundos engranajes con el pasado. Es consciente de lo pasado. Pero sufre una tormenta brutal: mira a lo hondo en el presente y fija sus miradas clarividentes en el porvenir. Esto no lo perdonan los que tan solo viven del pasado (1929, p. 7).

Estrada no tiene claro cómo llamar esa nueva poética que él mismo estudia y practica. A veces la llama "modernismo", otras, como en la cita anterior, "nueva poética", y en otros sitios alude a los autores vanguardistas como los "nuevos sensitivos". Esto evidencia lo que se ha señalado en este artículo como imprecisiones conceptuales debidas a la cercanía del autor con el contexto donde se están produciendo las escrituras de vanguardia. ${ }^{7}$ Asimismo, muestran a Estrada como un contemporáneo de su tiempo, en los términos señalados por Giorgio Agamben.
Esta compleja realidad tan llena de incertidumbre para Estrada lo lleva a criticar los excesos en los que han caído algunos de estos "nuevos sensitivos". Critica el afán por sumirse en la notoriedad o en arrebatos líricos inexplicables. Y ante esto, clama que "debemos demostrar que hay algo más grandioso en nosotros; algo que está por encima de la notoriedad" (1929, p. 8). Ese algo lo entiende el poeta como la aptitud, la cual ubica sobre la reproducción de ritmos, dado que los autores de la nueva poesía lo que trabajan son las mismas combinaciones rítmicas de la lengua pero procurando someterlas a leyes métricas con el fin de que sean aceptadas.

Finaliza el prólogo Estrada manifestando el deseo de que, ante el incierto panorama de la nueva poesía, llegue pronto el día de que sea aceptada como parte del canon literario:

No deseara sino ver el día en que, ya depurada, la poética nueva sea un canon aceptado por todas las gentes; debemos reconocer que muchos de los que nos impugnan a base de que somos incomprensibles, no entenderían tampoco a los clásicos si llegaran a leerlos (1929, p. 8).

Con base en estas ideas, procura Estrada legitimar su escritura vinculándola con la tradición. Y efectivamente, el poemario se orienta en esta dirección señalada por el prólogo. Se trata de textos que incorporan normas métricas, pero sin renunciar a la experimentación y la expresión de la subjetividad, tan valoradas por el poeta.

El poemario se compone de treinta y tres poemas, reunidos en seis secciones tituladas "Canciones", "Sonetos de un recién casado", "Recuerdos de México", "De la contemplación", "Cuatro canciones" y "Otras canciones".

Como se observa, Estrada echa mano de formas poéticas tradicionales como el soneto, dando privilegio a las canciones. En ellas busca la armonía vocálica, el ritmo y emplea la métrica heredada de la tradición clásica. Véase, por ejemplo, un fragmento del poema amoroso titulado

7 Jorge Cañizares Esguerra ha señalado esta misma distancia entre el sujeto de conocimiento y su objeto, como un elemento propio de la labor historiográfica: "Es un principio de la profesión de los historiadores el que solo el tiempo proporciona a los observadores la distancia para percibir las estructuras lingüísticas, económicas, políticas y culturales que configuran nuestras vidas” (2007, p. 19). 
"Cancionero mío": "Nunca jamás fui a tu boca, / pues tu boca vino a mí; / ni tú buscaste mi boca, / pues tu boca fue hacia ti” (1929, p. 26).

Sin embargo, el mayor énfasis del poemario es la clara intencionalidad de la voz lírica por sumergirse en su subjetividad, como lo hace en "Poemas en la noche":

Amo por eso las noches

y me sumerjo en ellas:

en sus nubes fantásticas,

en sus estrellas innumerables,

en sus innumerables promesas de mundos,

y en sus dóciles sombras,

dóciles a la fatalidad que nos rodea,

dóciles y fatales,

que lo sepultan todo en el espacio,

que lo sepultan todo en torno mío,

y lo unifican todo;

y que me hacen sentirme un punto viviente entre las sombras,

un punto como tantos que ignora mi conciencia,

o quizá como alguno de esos que hacen tintinear el firmamento (1929, p. 48).

Más allá de la demostración de que su poesía posee fuertes ataduras con el pasado y la presencia de canciones y sonetos, hay textos alejados de las intenciones musicales y métricas en los cuales Estrada profundiza en esa noción de la poesía como escritura experimental, la cual constituye una inmersión reflexiva en la exploración y la expresión de su subjetividad, tal como entendía el autor la "nueva poesía".

De esta manera, Canciones y ensayos despliega una estrategia de legitimación en el campo literario de la Costa Rica de principios del siglo XX, sin renunciar al núcleo de su poética, camino solitario, lleno de incertidumbres cuyo desarrollo fue súbitamente cancelado por la repentina y trágica muerte del autor.

\section{Conclusión}

Inmerso en los avatares de un incipiente campo cultural artístico, cuyas regulaciones estaban en manos de pocos agentes con poder simbólico, y todos ellos seguidores de los cánones románticos, modernistas y realistas, Rafael Estrada procuró asignarle un lugar a las estéticas de vanguardia en la Costa Rica de la segunda década del siglo XX.

Sin embargo, el autor se movía en las ambigüedades de la falta de distancia histórica para la comprensión de las nuevas escuelas y sus necesidades expresivas y representacionales. Así también el poeta vivió en las inseguridades de su limitado acceso a la formación artística (la cual era de orden autodidáctico) y mediado por el prestigio de las teorías estéticas idealistas de su tiempo.

Tales limitaciones enfrentan al intelectual costarricense con el dilema de valorar las nuevas corrientes estéticas frente a la tradición y la ruptura, en un medio con poco desarrollo teórico al respecto y con un completo desconocimiento de las nuevas tendencias renovadoras; además, él mismo contaba con menos de treinta años de edad. Todo ello le representaba grandes dificultades, que sin embargo, logró resolver de una manera satisfactoria dadas sus condiciones.

En el texto "Al margen de los Fantaseos de Andrés Avelino" (1923) logra distinguir el poeta la heterogeneidad de las producciones vanguardistas y sostiene que ellas se diferencian de la tradición al distanciarse de la mímesis predominante en el siglo XIX y volcarse, por el contrario, al mundo de la interioridad del sujeto. Con ello logra asignarle un lugar a esas nuevas corrientes dentro del campo cultural, si bien un espacio periférico respecto a las tendencias dominantes, pero solo este hecho implica méritos para Estrada, frente a un medio que simplemente rechazaba y ridiculizaba tales nuevas escuelas. Bastan estas consideraciones de Estrada para que ocupe un lugar distinguido y el papel de precursor en la crítica estética sobre las vanguardias en Costa Rica. 
Por la coyuntura que le correspondió vivir, Estrada no se separa de la tradición bellaletrística, sigue considerando el valor estético como un acto misterioso e intuitivo que corresponde con la identificación del arte en tanto sinónimo de verdad y belleza, tal como lo exigía su época.

Sobre los estudios estéticos (1926) es un texto más conservador en el cual el autor reflexiona sobre la teoría estética de su tiempo y concluye que es análoga al comentario estético, campo que no es productivo para la consideración de las nuevas escuelas de vanguardia. Concluye Estrada que hay que mirar estas tendencias con cuidado para comprender su valor en tanto producciones culturales. Hasta ahí puede llegar, no recupera su valiosa posición esbozada en el texto de 1923, la cual le habría permitido teorizar con mayor amplitud sobre las relaciones de las vanguardias con la tradición y con sus distancias respecto a ella.

En su último poemario Canciones y ensayos, y especialmente en el prólogo del texto, Estrada desarrolla como estrategia de legitimación, y con el afán de incidir para que los agentes dominantes del campo literario miren con mayor objetividad la nueva literatura, el vínculo de esa productividad con la tradición. Por ello recurre a los géneros de la canción y el soneto, pero sin renunciar a la exploración de la subjetividad y la experimentación expresiva.

El aporte de Rafael Estrada al estudio del lugar de las estéticas vanguardistas en el campo cultural latinoamericano y costarricense, gracias a los trabajos "Al margen de los Fantaseos de Andrés Avelino", Sobre los estudios estéticos y Canciones y ensayos es imprescindible y le otorga al autor un lugar fundacional en la historia de la crítica estética y literaria costarricense.

\section{Bibliografía}

Agamben, G. (2006). ¿Qué es lo contemporáneo? Recuperado el 9 de abril de 2021, de https:/ adultosmayores.unr.edu.ar/wp-content/ uploads/2020/o9/Agamben-Que-Es-LoContemporaneo-en-Desnudez.pdf
Alba de, F. (1929, 26 de enero). Canciones y ensayos por Rafael Estrada. La Nueva Prensa, 8 (2141), 5.

Avelino, A. (1924). Pequeña antología postumista. Santo Domingo: La cuna de América.

Bolaños, L. (1991). Literatura: aproximaciones de lectura. Signos, lenguajes y discursos sociales. Antología de la Cátedra de Comunicación y Lenguaje de la Escuela de Estudios Generales de la Universidad de Costa Rica. (194-209). San José: Nueva Década.

Bonilla, M.A. (1929, 24 de setiembre). Impresiones. La Nueva Prensa, 8 (2338), 7.

Bourdieu, P. (1995). Las reglas del arte. Génesis y estructura del campo literario. Trad. de Thomas Kaus. Barcelona: Anagrama.

Cañizares-Esguerra, J. (2007). Cómo escribir la historia del Nuevo Mundo. Trad. de Susana Moreno. México: Fondo de Cultura Económica.

Céspedes, D. (1985). Lenguaje y poesía en Santo Domingo en el siglo XX. Santo Domingo: Editora de la UASD.

Croce, B. (1938). Breviario de estética. Trad. de José Sánchez. Buenos Aires: Espasa Calpe.

Estrada R. (1923a, 29 de octubre). Al margen de los Fantaseos de Andrés Avelino. Repertorio Americano, 7 (6), 83-85.

Estrada R. (1923b, 5 de noviembre). Al margen de los Fantaseos de Andrés Avelino. Repertorio Americano, 7 (7), 104-106.

Estrada R. (1923c, 19 de noviembre). Al margen de los Fantaseos de Andrés Avelino. Repertorio Americano, 7 (9), 138-139.

Estrada R. (1926a, 17 de julio). Página lírica de Andrés Avelino. Repertorio Americano, 13 (3), 42-43. 
Estrada R. (1926b, 28 de agosto). Crítica americana, por J. Francisco Villalobos. Repertorio Americano, $13(8), 248$.

Estrada, R. (1926c). Sobre los estudios estéticos. San José: Imprenta Alsina.

Estrada R. (1927a, 22 de setiembre). El poeta Estrada se refiere a nuestro medio literario. La Nueva Prensa, 6 (1832), 11.

Estrada R. (1927b, 3 de noviembre). El poeta Estrada lanza un desafío a los literatos del país que adversan el modernismo. La Tribuna, 8 (2232), 2.

Estrada R. (1927c, 23 de noviembre). Métrica moderna. Primeros ejemplos para el conocimiento de la técnica de la poesía contemporánea. Diario de Costa Rica, 9 (2516), 3.

Estrada, R. (1929). Canciones y ensayos. San José: Ediciones del Convivio, Imprenta Alsina.

Fernández-Lobo, M. (1959). Las ideas estéticas de Rafael Estrada. Revista de Filosofía de la Universidad de Costa Rica, 2 (6), 55-57.

Huidobro, V. (1976). Altazor. En M. Céspedes (Ed.). Vicente Huidobro. San José: Ministerio de Cultura, Juventud y Deportes, 121-210.

Monge, C. F. (2005). El vanguardismo literario en Costa Rica. Heredia: Editorial de la Universidad Nacional.

Monge, C. F. y Baltodano, G. (2016). Para una periodización de la crítica literaria en Costa Rica. Letras, 6o, $15-44$.

Osorio, N. (1981). Para una caracterización histórica del vanguardismo hispanoamericano. Revista Iberoamericana, 47, 227-254.
Osorio, N. (1988) Manifiestos, proclamas y polémicas de la vanguardia literaria hispanoamericana. Caracas: Biblioteca Ayacucho.

Penélope. (1924, 17 de febrero). Huellas de la semana. La Tribuna, 5 (1381), 10.

Plaza, E. (2001). Influencia de Ruskin en la formación del estilo en Proust. Unas notas. Materia. Revista D’art, 1, 147-158.

Quesada-Soto, A. (1995). La formación de la narrativa nacional costarricense (1890-1910). San José: Editorial de la Universidad de Costa Rica.

Rodríguez-Cascante, F. (2017). Rafael Estrada y la distinción en el campo literario costarricense de la década de 1920. Revista de Filología y Lingüística de la Universidad de Costa Rica, 43 (2), 63-81.

Sotela, R. (1924). La educación estética. Repertorio Americano, 9 (4), 51-52.

Uribe, E. (1929, 14 de diciembre). Canciones y ensayos de Rafael Estrada. Repertorio Americano, 19 (23), 357.

Videla-de Rivero, G. (2011). Direcciones del vanguardismo hispanoamericano. 3 ed. Mendoza: Editorial de la Universidad Nacional de Cuyo.

Walmar, W. (1927, 30 de marzo). Brosas modernistas. Bohemia, 3 (67), 3. 